\title{
Dynamic Response of Reinforced Concrete Beams Following Instantaneous Removal of a Bearing Column
}

\author{
Ying $\operatorname{Tian}^{1)}$ and Youpo $\mathrm{Su}^{2)}$
}

(Received September 6, 2010, Revised March 3, 2011, Accepted May 31, 2011)

\begin{abstract}
This paper documents an experimental study of dynamic response of reinforced concrete beams following instantaneous removal of a bearing column. Four half-scale specimens representing two-span beam bridging across the removed column were tested. The test boundary conditions simulated rotational and longitudinal restraints imposed on a frame beam by the neighboring structural components. The gravity loads were simulated by attaching mass blocks on the beams at three locations. Dynamic loading effects due to sudden removal of a column were simulated by quickly releasing the supporting force at the middle of the specimens. The experimental study investigated the load-carrying capacity of beams restrained longitudinally at the boundaries and dynamic impact on forces. The tests confirmed the extra flexural strength provided by compressive arch action under dynamic loading. The tests also indicated that the dynamic amplification effects on forces were much lower than that assumed in the current design guideline for progressive collapse.
\end{abstract}

Keywords: compressive arch action, dynamic impact factor, dynamic response, progressive collapse, reinforced concrete beam.

\section{Introduction}

Local failure of primary structural components caused by abnormal loads not considered in a typical design can propagate and lead to a disproportionate collapse of partial or even entire structural system. To mitigate the risk of disastrous progressive collapse in buildings, existing design guidlines consider two approaches, indirect design and direct design, as described in ASCE 7-10 ${ }^{1}$ and DOD. ${ }^{2}$ Indirect design method emphasizes providing minimum levels of strength, continuity, and ductility to ensure structural integrity under abnormal loading events. The DOD guideline, ${ }^{2}$ require an integrated system of tie forces for developing tensile membrane or catenary action. In addition, the ACI 318-08 code $^{3}$ requires at least two beam bottom bars pass through the region bounded by the column longitudinal reinforcement. As one of the direct design approaches, alternative load path approach has been recommended. ${ }^{1,2}$ According to this approach, if a primary load-carrying component such as a column or a bearing wall is destructed during an extreme loading event, an alternative load path must be generated to resist the redistributed gravity loads. To examine the performance of reinforced concrete buildings following the loss of one or more bearing columns, numerical studies have been conducted by Hayes Jr. et al., ${ }^{4}$ Sasani and Kro-

\footnotetext{
${ }^{1)}$ Dept. of Civil Engineering, University of Nevada Las Vegas, 4505 S. Maryland Parkway, Las Vegas, NV 89119, USA. E-mail: ying.tian@unlv.edu

${ }^{2)}$ Hebei Earthquake Engineering Research Center, Hebei United University, No. 46 Xinhua West Street, Tangshan 063009, Hebei, China.

Copyright (c) 2011, Korea Concrete Institute. All rights reserved, including the making of copies without the written permission of the copyright proprietors.
}

pelnicki, ${ }^{5}$ Sasani and Sagiroglu, ${ }^{6}$ Bao et al., ${ }^{7}$ and Marchand et al. ${ }^{8}$ Findings obtained from the nonlinear static and dynamic analyses have resulted in an improved understanding of the progressive collapse potential of reinforced concrete structures.

Experimental data are essential for practices in progressive collapse prevention. ${ }^{9}$ However, very limited experimental data is available to date to calibrate the critical parameters used to define the strength and stiffness properties of structural components in nonlinear analysis modeling or to validate numerical simulation results. Sasani et al. ${ }^{10}$ instrumented an actual ten-story reinforced concrete building to examine its performance following the sudden removal of an exterior column by explosion. Same approach was used by Sasani and Sagiroglu ${ }^{11}$ to test a six-story reinforced concrete frame building, except that two adjacent exterior columns were demolished.

If a non-corner column is removed from a reinforced concrete frame structure, a two-span beam bridging over the removed column is formed. This two-span beam, interacting with the surrounding structural elements, is a critical structural component to develop an alternative load path to prevent a building from progressive collapse. The redistributed gravity load following column removal causes top concrete cracking due to negative bending at each end of the two-span beam and bottom cracking due to positive bending at the midspan where the column is removed. The uncracked portion of the beam presents geometry similar to an arch. Meanwhile, concrete cracking leads to a tendency of the beam to elongate axially. The elongation, however, is retrained by the surrounding components such as columns and slabs, which in turn causes compressive axial force in the beam. Consequently, the cracked beam behaves as an arch resisting both bending moment and axial compressive force. Such a compressive arch action can enhance the flexural capacity of a longitudinally 
restrained beam through axial force-flexure interaction, a property not considered in a normal design or analysis. Once the beam is further loaded with large deformation, the compressive axial force will gradually diminish, accompanying with the reduction of load carrying capacity. Depending on the beam flexural reinforcement ratio and span-to-depth ratio, tensile axial force may eventually develop at a deflection of about the beam height, leading to a catenary action that relies primarily on the tensile strength of longitudinal reinforcement to resist vertical loading. ${ }^{12}$ By testing twelve specimens under static loading, $\mathrm{Su}$ et al. ${ }^{12}$ studied the beneficial compressive arch effect and its application in progressive collapse resistance of reinforced concrete beams. The tests indicated that, depending upon the beam tensile reinforcement ratio and lengthdepth ratio, compressive arch action could enhance the vertical loading capacity of axially restrained beams by $40 \%$ to $130 \%$.

If a column is removed instantaneously, the remaining structure responses dynamically as if a step force equal to the supporting force provided by the removed column is suddenly applied in the opposite direction. As an extension to the work by Su et al., ${ }^{12}$ the experimental study reported herein investigated the dynamic performance of axially restrained beams. Such research is needed because it is largely unknown whether compressive arch action can also be effectively developed in the two-span beam under dynamic loading. This is due to the fact that compressive arch action is a function of the development of flexural cracking, but a beam may develop less flexural cracks under fast loading than under static loading condition. Although the progressive collapse resistance provided by a frame beam may be contributed by both compressive arch action and catenary action, the latter was beyond the scope of the study and thus not examined. In addition, the study did not explicitly address the effect of strain rate on concrete as that studied by Wei et al. ${ }^{13}$ and Quintero et al. ${ }^{14}$

\section{Theoretical background - nonlinear SDOF system analogy}

It is instructive to discuss the dynamic response of an idealized elastic-perfectly plastic single-degree-of-freedom (SDOF) system prior to the description of the experimental program and results. As shown in Fig. 1, this nonlinear system contains a cantilevered beam resisting the gravity load $P$ associated with a lumped mass placed at the beam free end. The beam is assumed to have a load-

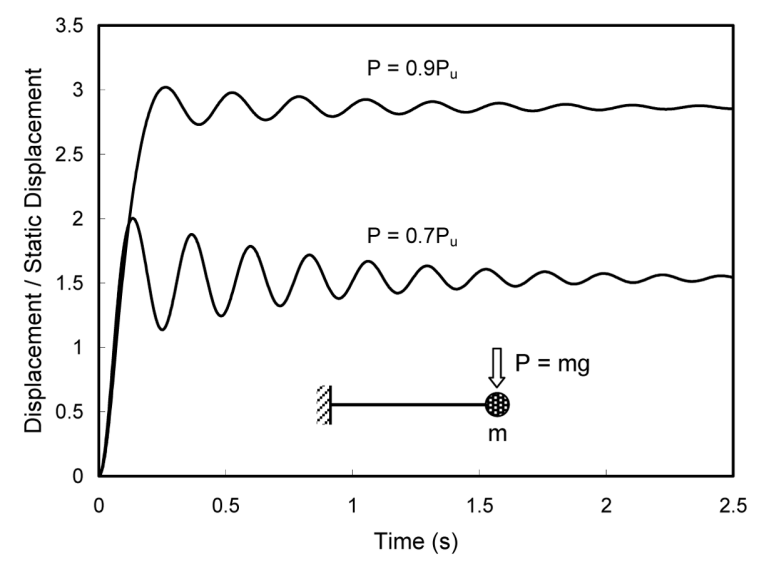

Fig. 1 Dynamic responses of a nonlinear SDOF system. carrying capacity of $P_{u}$ corresponding to the formation of plastic hinge at the beam fixed end. If the gravity load is slowly applied, it causes a static displacement at the lumped mass denoted as $u_{s t}$. However, if the gravity load is applied instantaneously, the beam is essentially subjected to a step force with a magnitude of $P$ that triggers a dynamic response. Note that this dynamic loading condition is equivalent to the scenario that a vertical support is initially placed at the lump mass to fully carry the gravity force $P$ and then suddenly removed. The dynamic response of this nonlinear system depends on the level of gravity load $P$ applied on the beam. The following discussion provides formulation of dynamic response for this SDOF system if it is undamped.

If $P \leq 0.5 P_{u}$, the system behaves elastically and the dynamic response due to the suddenly applied step force $P$ is described as ${ }^{15}$

$$
u(t)=u_{s t}\left(1-\cos \omega_{n} t\right)
$$

where $\omega_{n}$ is the natural period of the system. The dynamic response factor, defined as the ratio of the maximum dynamic response to the static response, is equal to 2 for both force and deformation. If $P \geq P_{u}$, the beam fails due to the formation of a collapse mechanism and the infinite plastic deformation demand nearby the support. If $0.5 P_{u}<P<P_{u}$, beam plastic hinge is generated in the SDOF system due to yielding. The displacement of the lumped mass at yielding that happens at time $t=t_{1}$ is denoted herein as $u_{y}$ Based on Eq. (1), the velocity of the lumped mass at beam yielding, $\dot{u}\left(t_{1}\right)$, can be derived as

$$
\dot{u}\left(t_{1}\right)=\frac{P_{u}}{\omega_{n} m} \sqrt{\frac{2 P}{P_{u}}-1}
$$

When, $t>t_{1}$, stiffness of the SDOF system diminishes due to yielding at $t=t_{1}$. The dynamic response thereafter is defined by

$$
m \ddot{u}(t)+P_{u}=P
$$

Taking the displacement $u_{y}$ and velocity $\dot{u}\left(t_{1}\right)$ of the lumped mass at $t=t_{1}$ as the initial condition, the equation of motion of the SDOF system can be solved from Eq. (3) as

$$
\begin{aligned}
& u(t)= \\
& \frac{P_{u}}{\omega_{n}^{2} m}\left[\frac{1}{2}\left(\frac{P}{P_{u}}-1\right)\left(\omega_{n} t-\omega_{n} t_{1}\right)^{2}+\sqrt{\frac{2 P}{P_{u}}-1}\left(\omega_{n} t-\omega_{n} t_{1}\right)+1\right]
\end{aligned}
$$

By setting $\dot{u}(t)=0$, the peak dynamic displacement response $u_{\max }$ can be determined from Eq. (4) as

$$
u_{\max }=\frac{P_{u}}{2 \omega_{n}^{2} m\left(1-\frac{P}{P_{u}}\right)}
$$

Note that if the load $P$ is applied as a static load, it causes a displacement equal to

$$
u_{s t}=\frac{P}{k}=\frac{P}{\omega_{n}^{2} m}
$$


Thus, it can be derived from Eqs. (5) and (6) that

$$
\frac{u_{\max }}{u_{s t}}=\frac{1}{2\left(1-\frac{P}{P_{u}}\right)\left(\frac{P}{P_{u}}\right)}
$$

It can be seen from Eq. (7) that, if $P_{u}<P<0.5 P_{u}$, the dynamic response factor for deformation is greater than 2 but with a limited value.

If the SDOF system is damped, the deformation demand caused by the step force $P$ is reduced. Fig. 1 shows the dynamic displacement response normalized by static displacement for the aforementioned SDOF system with a natural period of $0.23 \mathrm{sec}$ and a viscous damping ratio of $\xi=5 \%$. As the gravity load $P$ approaches $P_{u}$, the steady-state displacement of the system becomes closer to its peak dynamic response $u_{\max }$ due to large residual plastic deformation. Thus, the ratio of the maximum deflection to the steadystate deflection indicates the degree of the applied load $P$ approaching the load capacity of the beam $P_{u}$. The criterion adopted in $\mathrm{DOD}^{2}$ for flexural design is that, the deformation demand at beam plastic hinges imposed by dynamic loading shall not exceed the deformation capacity provided by the beam in order to maintain vertical load carrying capacity. As implied in Eq. (7) and shown in Fig. 1, the dynamic deformation demand caused by a step force $P$, however, is sensitive to the $P / P_{u}$ ratio if the elastic limit of a SDOF system is exceeded. Therefore, if the concept of the SDOF system analogy can be extended to a reinforced concrete beam resisting progressive collapse, its flexural capacity should be evaluated with reasonable accuracy to avoid an unnecessary overestimation of deformation demand.

\section{Experimental program}

\subsection{Test subassemblies}

The experimental program consisted of testing four specimens denoted as D1 to D4. These specimens simulated a portion of a reinforced concrete frame building (shown in Fig. 2(a)) subjected to the sudden loss of a column in the first story. The specimens, with a 1/2-scale from the beams of the prototype building, had identical dimension shown in Fig. 2(b). Each test subassembly contains two beams framing with one center column stub and two short edge columns. Each beam segment was 2,700 mm long, $300 \mathrm{~mm}$ deep, and $150 \mathrm{~mm}$ wide. The center column represented the removed column and was $300 \mathrm{~mm}$ square. The edge columns had a cross section of $400 \times 250 \mathrm{~mm}$ and a height of $600 \mathrm{~mm}$. The edge beams had enlarged size for convenience of applying boundary conditions during the tests. Specimen D1, as a control specimen, was applied only with rotational restraint at each end. However, for Specimens D2, D3, and D4, both rotational and axial restraints were applied.

The specimens were constructed using ready-mixed normalweight concrete with cube compressive strength ranging from 25.0 MPa to 28.4 MPa. Deformed steel bars were used as beam longitudinal reinforcement. Each specimen had four $14 \mathrm{~mm}$ diameter bars continuous through the entire specimen, two as top reinforcement and two as bottom reinforcement. Additional beam longitudinal reinforcement was used to resist bending moment at the edge and center columns. These bars were curtailed outside the critical section with a distance of at least $550 \mathrm{~mm}$ based on the calculated moment envelop curve and satisfying the ACI 318-08 ${ }^{3}$ development length requirement. The longitudinal bars were extended into the edge columns and anchored with 90-degree hooks. The clear concrete cover was $20 \mathrm{~mm}$ measured from beam surface to the nearest longitudinal reinforcement. Closed hoops using smooth steel bars with 135-degree seismic hooks were used as transverse reinforcement. All the columns of a specimen were heavily reinforced to ensure an elastic behavior throughout testing.

Specimens D1 and D2 were identically reinforced and simulated a beam originally designed to resist seismic loads in an actual building. The top reinforcement ratio of these beams was $1.24 \%$ and bottom reinforcement ratio was $0.75 \%$. It is noted that, although different beam top reinforcement was used at the edge and the center columns, the yield strength and reinforcement ratio at these locations were very similar. The transverse reinforcement of Specimens D1 and D2 had a close spacing of $100 \mathrm{~mm}$ to obtain sufficient shear strength and confinement effects as required in a seismic design. These specimens were used to study the compressive arch effects on beam stiffness and flexural strength under dynamic loading and to study the potential progressive collapse resistance of a beam with seismic designs.

Specimens D3 and D4 simulated the beams designed explicitly according to the alternative load path approach to bridge over the

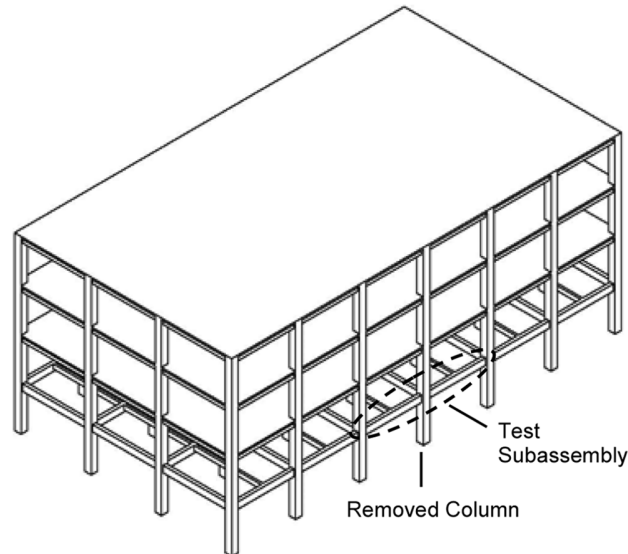

(a) Prototype structure
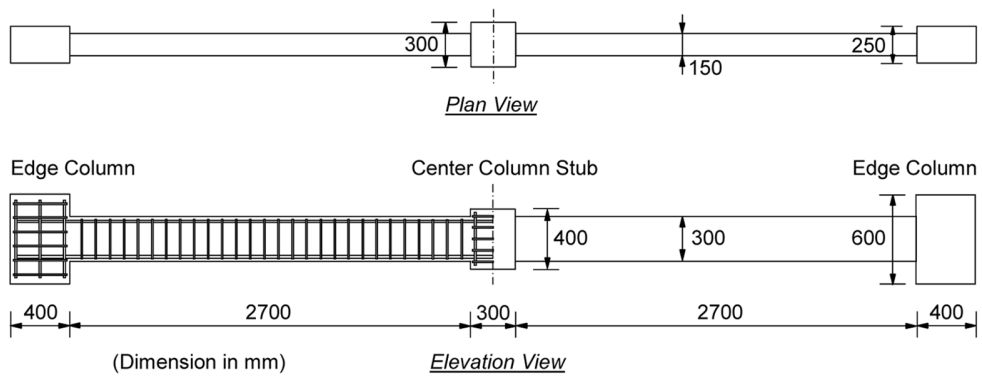

(b) Test subassembly

Fig. 2 Prototype structure and test subassembly configuration. 
missing column and sustain the redistributed internal forces following column removal. Thus, the beams of these specimens were designed to resist negative bending moment at the edge columns and positive bending moment at the center column. The transverse reinforcement of these specimens was designed to avoid premature shear failure during testing. Because of the higher shear demand, the spacing of transverse reinforcement of beam at the supports doubled that at the midspan. The beam tensile reinforcement ratio at the edge column (top in tension) was $1.79 \%$ and $2.39 \%$ for Specimens D3 and D4, respectively. The beam tensile reinforcement ratio at the center column (bottom in tension) was $1.03 \%$ and $1.38 \%$ for Specimens D3 and D4, respectively.

Table 1 provides reinforcement layout of the tested specimens, tensile reinforcement ratio $\rho$, and cube compressive strength $f_{c u}$ of concrete measured at the start of a test. Table 2 givens the measured yield and ultimate strength of reinforcing bars.

\subsection{Test setup and loading scheme}

Fig. 3(a) schematically shows the test layout planned in this study to apply boundary restraints on the test subassemblies and to simulate the dynamic loading effects caused by the instantaneous removal of a supporting column in the prototype building. Each edge column of a specimen was vertically supported by two links. The location of the inner links at points A and B simulated the beam-column joint centers of the prototype structure. Rotational restraints at the edge columns were provided by the outer links at $\mathrm{C}$ and $\mathrm{D}$, where the vertical restraining force $F$ was measured. Except for Specimen D1, the longitudinal displacement of the edge columns was restrained and the resulting horizontal reaction force $N$ was measured. One lumped mass was placed at the center column and two others at the quarter-spans of a specimen. These lumped masses, each with a weight of $P$, were used to simulate the gravity loads transferred to the two-span beam from the transverse components of the prototype building. An upward force with a magnitude of $2 P$ was applied to a specimen at the center column to simulate the supporting force initially provided by the lost column, and was then quickly released to simulate the sudden removal of this column. It is noted that, in an actual reinforced concrete frame system, the gravity load initially carried by the lost column will be resisted after column removal by not only the twospan beam but also the neighboring floor slabs and transverse beams. Thus, the test setup used in this study cannot fully simulate such complex load redistribution.

Fig. 3(b) illustrates the actual test setup used to accomplish the test scheme described above. A test bed shown in Fig. 3(c) was specially designed to support the specimens and to apply desired boundary conditions at the edge columns. Prior to a test, the edge columns were anchored into the steel sockets that were vertically
Table 2 Reinforcement properties.

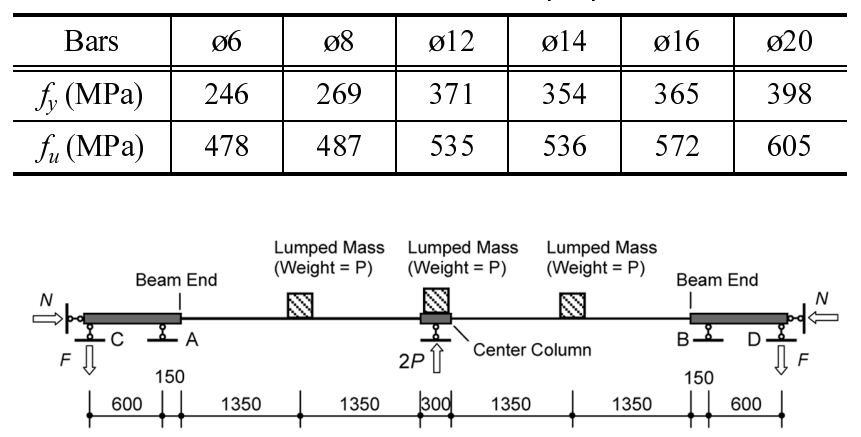

(a)

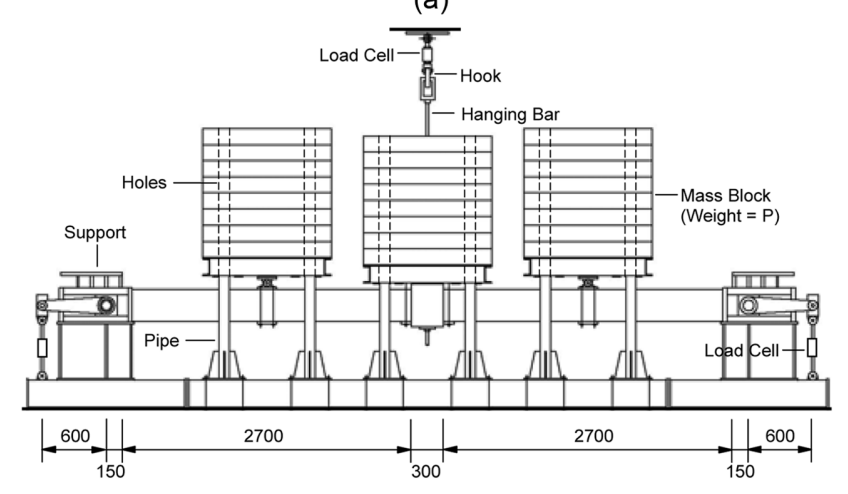

(b)

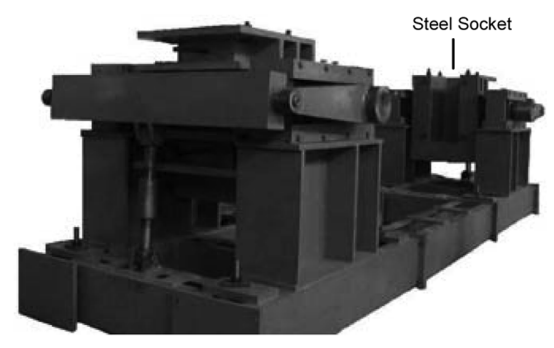

(c)

Fig. 3 Test setup (all dimension in $\mathrm{mm}$ ).

supported in the test bed. The sockets were then further connected with the vertical struts shown in Fig. 3(c) to restrain the rotation of the steel sockets and thus the rotation of the edge columns. Finally, the longitudinal restraint to a specimen was applied by limiting horizontal movement of the steel sockets.

After a specimen was assembled with the test bed, the center column stub was temporarily shored. Mass blocks made of concrete and cast iron were stacked and anchored on the beams. The mass blocks at each of the three loading locations had an equal weight of $P$. The mass blocks were fabricated with sleeve holes that permitted the pipes installed on the test bed to penetrate and guide the mass blocks to displace only in the vertical direction during a test. A hanging bar was used to connect the center column

Table 1 Specimen properties.

\begin{tabular}{|c|c|c|c|c|c|c|c|c|c|}
\hline \multirow{2}{*}{ Specimen } & \multirow{2}{*}{$f_{c u}(\mathrm{MPa})$} & \multicolumn{4}{|c|}{ Reinforcement of beam at edge columns (supports) } & \multicolumn{4}{|c|}{ Reinforcement of beam at center column (midspan) } \\
\hline & & Top bar & Bottom bar & Tie & $\rho$ (tension) & Top bar & Bottom bar & Tie & $\rho$ (tension) \\
\hline D1 & 27.0 & $2 ø 14+1 ø 16$ & $2 ø 14$ & ø8@200 & $1.24 \%$ & $2 \varnothing 14+2 \varnothing 12^{\dagger}$ & $2 ø 14$ & ø8@200 & $0.75 \%$ \\
\hline D2 & 25.7 & $2 ø 14+1 ø 16$ & $2 ø 14$ & ø8@200 & $1.24 \%$ & $2 \varnothing 14+2 \varnothing 12^{\dagger}$ & $2 ø 14$ & ø8@200 & $0.75 \%$ \\
\hline D3 & 28.4 & $2 ø 14+2 \varnothing 16^{\dagger}$ & $2 ø 14$ & ø6@100 & $1.79 \%$ & $2 ø 14$ & $2 ø 14+1 \varnothing 12$ & ø6@200 & $1.03 \%$ \\
\hline D4 & 25.0 & $2 \varnothing 14+2 \varnothing 20^{\dagger}$ & $2 ø 14$ & ø6@75 & $2.39 \%$ & $2 ø 14$ & $2 ø 14+2 ø 12^{\dagger}$ & ø6@150 & $1.38 \%$ \\
\hline
\end{tabular}

Two rows of longitudinal bars were used. 
stub with the beam of a loading frame situated above a specimen. An upward force was applied to specimen by adjusting the length of hanging bar until a force of $2 P$ measured from the load cell shown in Fig. 3(b) was developed in the hanging bar. The dynamic response of a specimen was triggered by unlocking the hook connecting the load cell and the hanging bar. The hook was devised so that the hanging force could be completely released within $0.008 \mathrm{sec}$. This short time was less than $10 \%$ of the natural period of all specimens and thereby enabled the simulation of dynamic loading effects imposed by a step force.

Each specimen was subjected to multiple tests using different weight $P$ of the mass blocks. The weight $P$ is referred for convenience as applied load in the following discussion. The dynamic tests of a specimen started from lower level of load $P$. Once the test at a load level was completed, the mass at each loading location was equally increased and the supporting force at the center hanging bar was correspondingly adjusted to perform the test at a new load level. The lower loads were used to study the dynamic response of a specimen within its elastic range. The higher loads were used to examine the flexural strength properties of a specimen. The number of tests for a specimen and the magnitude of load $P$ were adjusted based on the observations from the previous tests. Note that, unlike a static loading test, the dynamic test scheme employed in this study cannot exactly identify the maximum gravity load that can be placed at each loading position without flexural failure. However, a lower bound (minimum) load capacity of the specimens under compressive arch action, $P_{u, m i n}$, can be determined from the highest applied load that did not result in a flexural failure.

The specimens were instrumented with three types of sensors: load cells measuring the horizontal restraining force $N$, the vertical restraining force $F$, and the hanging force $2 P$; LVDTs measuring the vertical displacements at the mid- and quarter-spans; and strain gauges measuring the tensile strain of longitudinal and transverse reinforcement at selected locations. The test data were simultaneously collected at a sampling rate of $1000 \mathrm{~Hz}$ by a data acquisition system. From the measured vertical restraining force $F$, the restraining moment $M_{0}$ at the edge column can be determined as $0.6 F(\mathrm{kN}-\mathrm{m})$. Because the test bed was designed initially for the static loading tests by Su et al., ${ }^{12}$ the beam shearing forces caused by inertia forces could not be directly determined.

\section{Experimental results and discussion}

\subsection{Overall response under lower loads}

It was found from tests that the first vibration mode dominated the response of all specimens. Depending on the gravity load level $P$, the maximum deformation response occurred between 0.07 and $0.27 \mathrm{sec}$. For all specimens, their dynamic response ended at a steady-state within $2 \mathrm{sec}$. The deflection-time history recorded at the center column of the specimens is shown in Fig. 4 for lower loading $(P \leq 13.7 \mathrm{kN})$. Flexural cracking occurred in the beams even at the lowest load level, which resulted in a horizontal restraining force measured at the specimen boundaries. Fig. 5 shows as an example the response of Specimen D2 at $P=13.7 \mathrm{kN}$ for three types of measurement. As seen in this figure, the deflections at the mid- and quarter-spans, the horizontal restraining force $N$, and the restraining moment $M_{0}$ at the edge columns responded
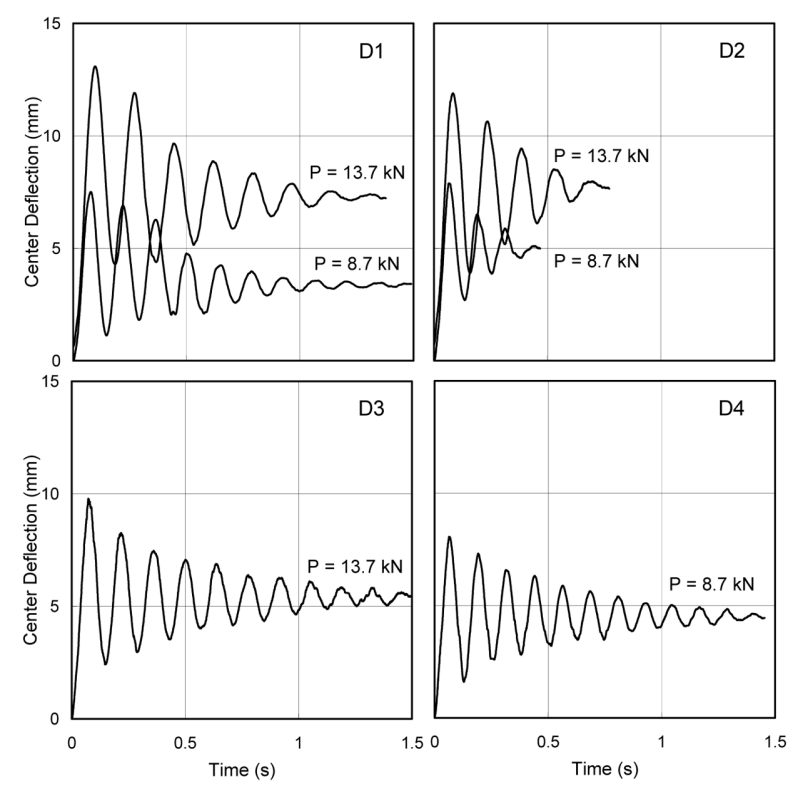

Fig. 4 Center deflection-time history at lower loads.
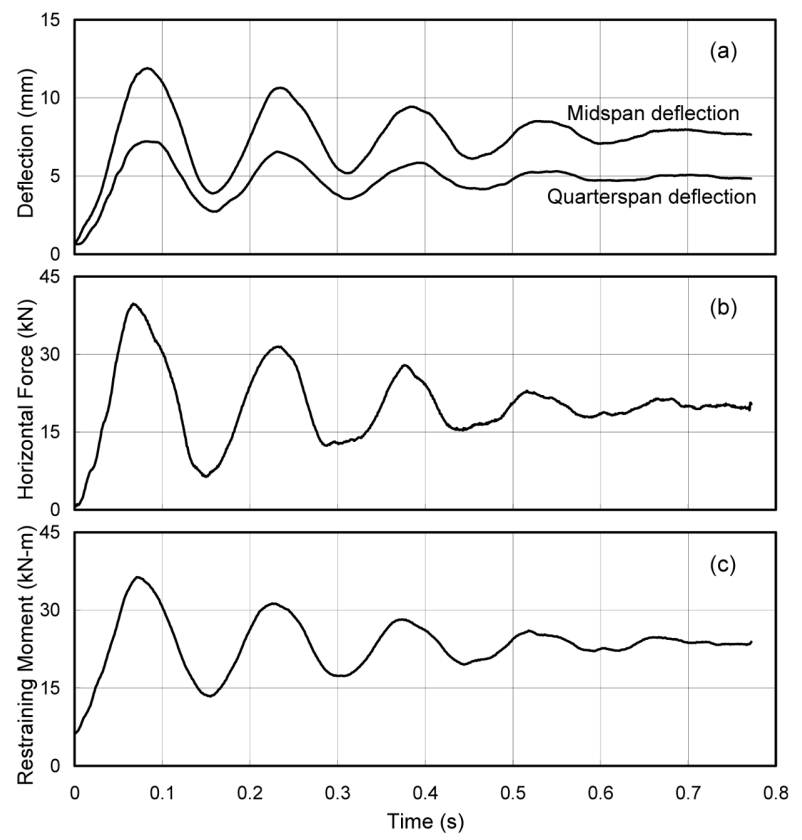

Fig. 5 Dynamic response of Specimen D2 $(P=13.7 \mathrm{kN})$ : (a) deflections at mid- and quarter-spans; (b) horizontal restraining force; and (c) restraining moment.

approximately in the same phase.

Because of the dominance of the first mode, a viscous damping ratio $\xi$ for this vibration mode can be estimated for the specimens using Eq. (8) based on the decaying peak center deflections $\delta_{1}$ and $\delta_{4}$ measured at the first and fourth cycles of vibration.

$$
\ln \frac{\delta_{1}}{\delta_{4}}=\frac{6 \pi \xi}{\sqrt{1-\xi^{2}}}
$$

The estimated damping ratios of most specimens under lower loading ranged from 4 to $6 \%$, which is consistent with the typically assumed 5\% damping ratio for a cracked reinforced concrete structure in seismic time-history analysis. 
Under the loads of $P=8.7$ and $13.7 \mathrm{kN}$, the vibration period of Specimen D2, evaluated based on the first four cycles of deflection response, was $11 \%$ and $13 \%$ shorter than the vibration period of Specimen D1. This indicated that, as compared with Specimen D1 which was free for longitudinal elongation, the axial restraint applied to Specimen D2 has increased beam flexural stiffness.

\subsection{Overall response under higher loads}

Fig. 6 shows the deflection-time history at the center column for specimens under higher loads $(P \geq 18.8 \mathrm{kN})$. The characteristic loading stages including flexural yielding and concrete crushing are denoted for each specimen in this figure. To protect equipment and to ensure safety during the fast dynamic loading tests, the maximum center deflection of specimens was restrained. Therefore, catenaty action was not mobilized in a specimen even following its concrete crushing. Due to concrete cracking, the tests of a specimen under lower loads have caused residual deformation. More residual deformation was accumulated under higher loads before the test at a newer loading level was performed. It was found from test data that once flexural yielding has occurred in a specimen, its dynamic response decayed at a much faster rate than in the lower levels of loading. If Eg. (8) is used again to examine the damping property, all specimens would have a viscous damping ratio larger than $10 \%$.

Specimens D1 and D4-For convenience of presenting test results, the applied load levels are represented herein as a function of $P_{y u} . P_{y u}$ is defined as the plastic load-carrying capacity of a specimen at the formation of a collapse mechanism under the three-point loading condition used in the tests. $P_{y u}$ was evaluated for each specimen following the conventional approach based on $M_{u, 1}$ and $M_{u, 2}$, the beam pure flexural strength at the supports and midspan without considering compressive arch effects. Loads lower than $P_{y u}$ were first applied to these specimens. Under the load of $P=18.8 \mathrm{kN}\left(0.75 P_{y u}\right)$ applied to Specimen D1 and 28.9 $\mathrm{kN}\left(0.67 P_{y u}\right)$ to $\mathrm{D} 4$, no flexural yielding was identified during the dynamic response. Increased gravity loads approximately equal to $P_{y u}$ were then applied to these specimens. Under the load of $P=$
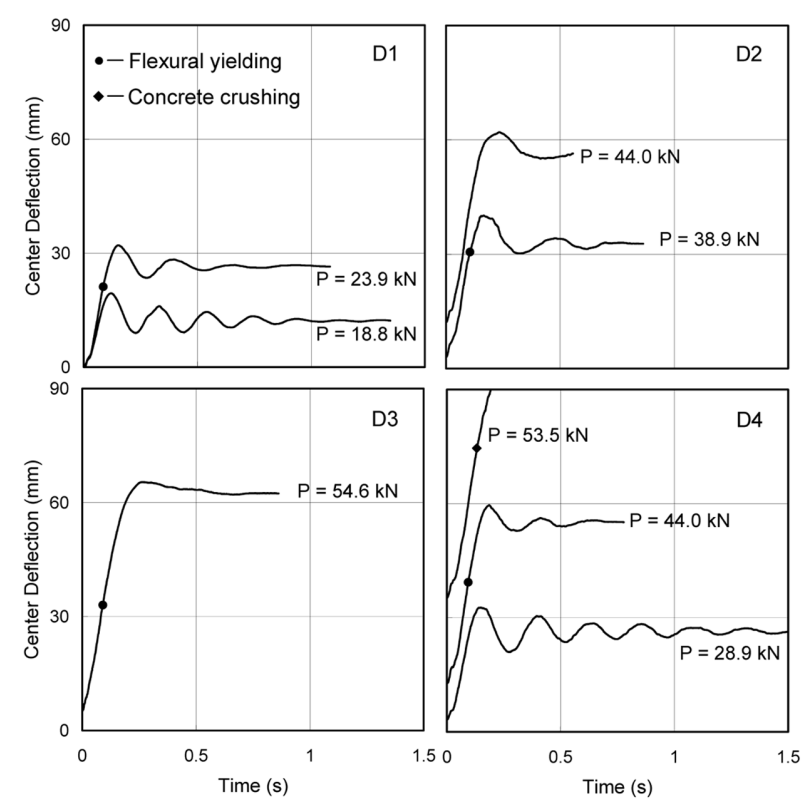

Fig. 6 Center deflection-time history at higher loads.
$23.9 \mathrm{kN}\left(0.95 P_{y u}\right)$ for Specimen D1 and $44.0 \mathrm{kN}\left(1.02 P_{y u}\right)$ for D4, longitudinal reinforcement yielded at both the sports and the midspan but no flexural failure due to concrete crushing was observed. Because no compressive arch effect existed in Specimen D1 and very limited compressive arch effect could be expected for Specimen D4 due to its high reinforcement ratio, the weight of the mass blocks was increased slightly for further dynamic loading tests. At $P=28.9 \mathrm{kN}\left(1.15 P_{y u}\right)$ for Specimen D1 and $P=53.5 \mathrm{kN}$ $\left(1.24 P_{y u}\right)$ for $\mathrm{D} 4$, concrete crushing occurred at both the supports and the midspan. Following concrete crushing, the beams of D1 and D4 kept deforming until the vertical displacement at the center column was completely restrained. Thus, virtually no vibration occurred in these specimens due to flexural failure. Fig. 7 shows beam damage condition at the left side of the center column of Specimen D4 upon the completion of loading $(P=53.5 \mathrm{kN})$. The response of Specimen D1 at this load level $(P=28.9 \mathrm{kN})$ was not presented in Fig. 6, because the center deflection was not successfully measured by LVDT.

Specimens D2 and D3-Because of the enhanced load-carrying capacity anticipated from compressive arch action, a load of $P=$ $38.9 \mathrm{kN}\left(1.56 P_{y u}\right)$ and $54.6 \mathrm{kN}\left(1.62 P_{y u}\right)$ was applied to Specimens D2 and D3. Although these specimens sustained this level of loading with only flexural yielding, Specimen D3 has experienced severe damage in the beams. Fig. 8 shows the damage pattern of Specimen D3 at the completion of testing. Concrete spalling due to compression has occurred at the midspan and the loading has also caused a pronounced diagonal shear crack nearby the edge columns. The shear crack shown in Fig. 8(b) had a width of $3 \mathrm{~mm}$ that has resulted in yielding of transverse reinforcement

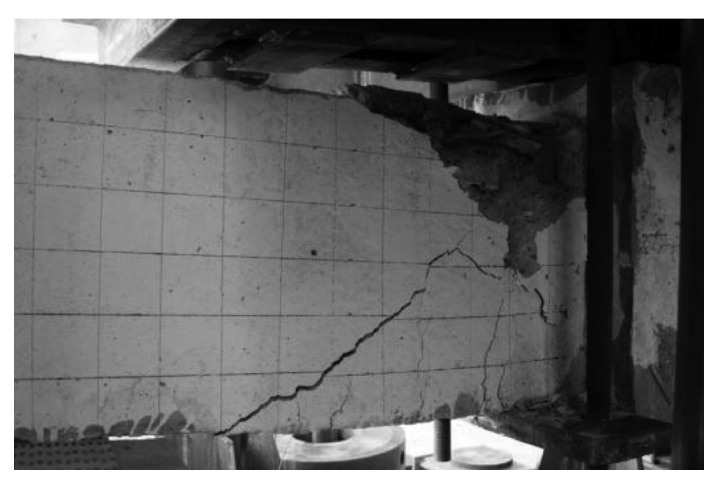

Fig. 7 Damage pattern of Specimen D4 at center column ( $P$ $=53.5 \mathrm{kN})$.

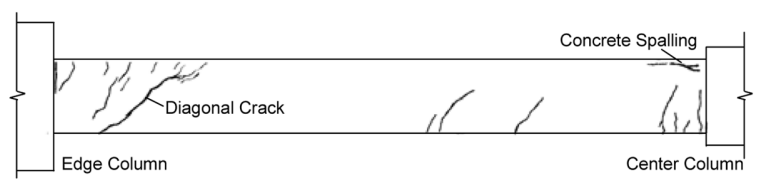

(a) Damage pattern of Specimen D3 $(P=54.6 \mathrm{kN})$

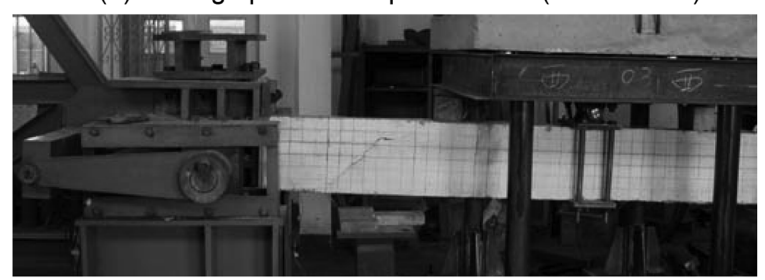

(b) Close-up of Specimen D3 at $P=54.6 \mathrm{kN}$

Fig. 8 Damage pattern of Specimen D3. 
crossing the inclined crack. Because severe damage has occurred in this specimen, testing was stop at this load level. For the next level of loading on Specimen D2, additional mass blocks corresponding to a load of $P=44.0 \mathrm{kN}\left(1.76 P_{y u}\right)$ were placed at each loading position. Specimen D2 withstood this level of loading. However, extensive damage due to flexural and shear cracking has occurred and thus no further test was performed on this specimen.

\subsection{Response of restraining moment and axial force under higher loads}

Fig. 9 shows the typical response of restraining moment $M_{0}$ at the right support and the response of the horizontal restraining force $N$ developed at the beam boundaries for three laterally restrained specimens under the highest level of load: D2 at $P=$ $44.0 \mathrm{kN}, \mathrm{D} 3$ at $P=54.6 \mathrm{kN}$ and D4 at $P=53.5 \mathrm{kN}$. The restraining moment response is plotted in the upper half of a figure and the horizontal restraining force causing compressive axial force is shown in the lower half. Because the vertical deflection of these beams was far less than their length $(<1 / 40)$, the measured horizontal restraining force can be approximated as the axial force developed in the beams. All specimens developed substantial compressive axial force in the beams that generally decreased with the increased tensile reinforcement ratio (Specimen D2 has the lowest reinforcement ratio and D4 has the highest reinforcement ratio). The ratio of $N_{\max }$, the maximum compressive restraining force, to $N_{u}$, the axial load capacity at the supports evaluated using ACI $318-08^{3}$, was $0.18,0.13$, and 0.07 for Specimens D2, D3, and D4, respectively.

As shown in Fig. 9, the axial force and restraining moment increased simultaneously once the dynamic response was initiated. Even though flexural yielding has occurred and the maximum restraining moment $M_{0, \max }$ has been achieved in Specimens D2 and D3, the axial force could still increase and started decreasing after the peak deflection was reached during the first cycle of vibration. Due to the fast load rate, it was difficult to capture the time when concrete crushing occurred in Specimen D4. However, the static loading tests carried out by $\mathrm{Su}$ et al. ${ }^{12}$ indicated that a flexural failure due to concrete crushing led to a decrease of compressive axial force in a beam. Fig. 9(c), according to this observation, suggests that concrete crushing of Specimen D4 occurred at $t$ $=0.13 \mathrm{sec}$ when the compressive axial force started decreasing. Same as the observation obtained in the static loading tests for specimens with similar span/depth ratios, ${ }^{12}$ the maximum restraining moment at the supports decreased in a fairly gradual manner.

The flexural behaviors of the specimens were further examined by the response of restraining moment as a function of the mea-

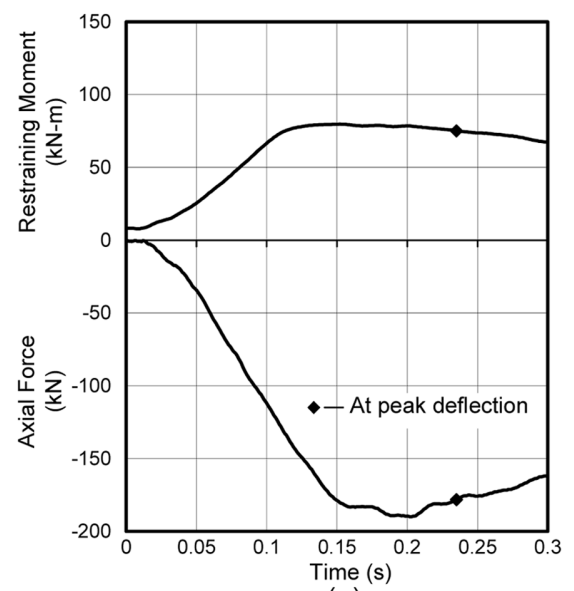

(a)

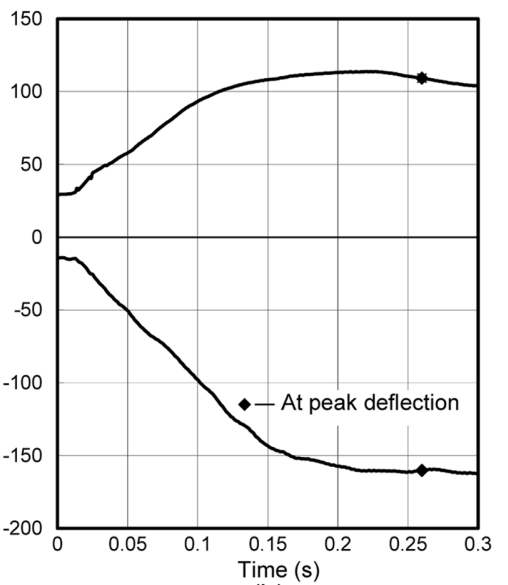

(b)

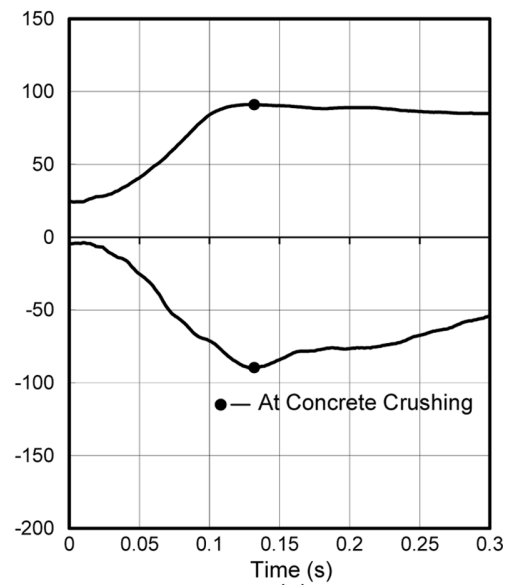

(c)

Fig. 9 Response of restraining moment and axial force: (a) Specimen D2 ( $P=44.0 \mathrm{kN})$, (b) Specimen D3 $(P=54.6 \mathrm{kN})$, and (c) Specimen D4 $(P=53.5 \mathrm{kN})$.

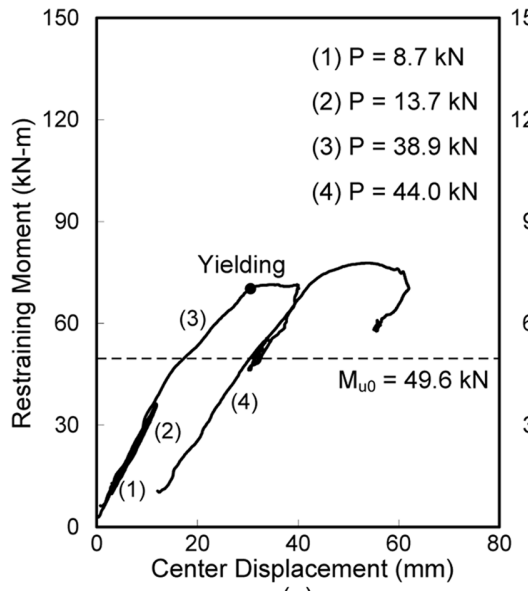

(a)

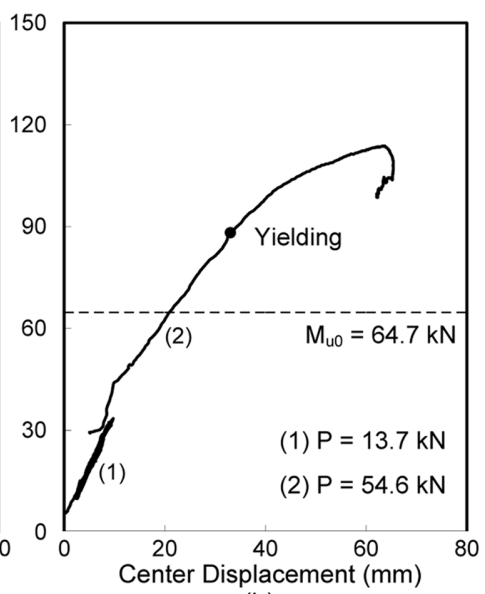

(b)

Fig. 10 Restraining moment versus center deflection: (a) Specimen D2, and (b) Specimen D3. 
Table 3 Restraining moments and axial forces.

\begin{tabular}{c|c|c|c|c|c}
\hline Specimen & $\begin{array}{c}N_{\max } \\
(\mathrm{kN})\end{array}$ & $N_{\max } / N_{u}$ & $\begin{array}{c}M_{u 0} \\
(\mathrm{kN}-\mathrm{m})\end{array}$ & $\begin{array}{c}M_{0, \max } \\
(\mathrm{kN}-\mathrm{m})\end{array}$ & $M_{0, \max } / M_{u 0}$ \\
\hline \hline $\mathrm{D} 1$ & - & - & 50.0 & 53.8 & 1.08 \\
\hline $\mathrm{D} 2$ & 190 & 0.179 & 49.6 & 77.7 & 1.57 \\
\hline $\mathrm{D} 3$ & 162 & 0.133 & 64.7 & 113 & 1.75 \\
\hline $\mathrm{D} 4$ & 89.6 & 0.074 & 81.6 & 97.6 & 1.20 \\
\hline
\end{tabular}

sured center deflection. Such a response at all levels of loading is shown in Figs. 10(a) and (b) for Specimens D2 and D3. Under the lower loads, axial force restrained concrete cracking of the beams, thereby resulting in an approximately linear moment-deflection response. Under higher loading, the maximum restraining moment $M_{0, \max }$ was only slightly higher than the restraining moment at yielding in Specimen D2. Specimen D3, however, presented more strain hardening than Specimen D2. The results of maximum restraining moment at the supports $M_{0, \max }$, maximum compressive axial force $N_{\max }$, and the ratios of $N_{\max }$ to $N_{u}$ under the highest level of loads are summarized for each specimen in Table 3.

\subsection{Dynamic load-carrying capacity under compressive arch action}

To illustrate the load-carrying capacity of the tested specimens under compressive arch action, the restraining moment at the reach of $P_{y u}$ (neglecting compressive arch effects), $M_{u 0}$, was calculated and compared with $M_{0, \max }$, the maximum restraining moment measured in the tests. Table 3 provides the values of $M_{0, \text { max }} / M_{u 0}$ ratio for the four specimens. Note that, although the restraining moment is not exactly equal to the beam bending moment at the supports, the $M_{0, \max } / M_{u 0}$ ratio can still be treated as a indicator of the enhancement of beam flexural capacity due to compressive arch action. It is seen from Table 3 that, because no compressive arch action existed in Specimen D1, $M_{0, \max }$ was approximately equal to $M_{u 0}$. Due to the high flexural reinforcement ratio of beams at the supports, $M_{0, \max }$ of Specimen D4 was only $20 \%$ higher than $M_{u 0}$. Specimens D2 and D3, however, demonstrated significantly enhanced flexural capacity as indicated by their much higher $M_{0, \text { max }} / M_{u 0}$ ratios. Thus, the tests confirmed the compressive arch effects on the flexural strength of axially restrained beams under dynamic loading conditions. Moreover, the performance of Specimen D2 indicated that a seismically designed beam processes inherent progressive collapse resistance.

Note that although dynamic loading was applied to the specimens, the effect of loading rate on beam flexural strength was difficult to evaluate, because the flexural strength and the peak rate of deformation may not be reached in a beam simultaneously. For instance, the maximum displacement velocity at the center column of Specimen D3 at the load of $P=54.6 \mathrm{kN}$ was estimated from the deflection-time history as $400 \mathrm{~mm} / \mathrm{sec}$ when flexural reinforcement yielded at $t=0.108 \mathrm{sec}$ during the first cycle of vibration. However, because of the energy absorbed by steel yielding, the deflection rate was drastically reduced to $60 \mathrm{~mm} / \mathrm{s}$ when $M_{0, \max }=113 \mathrm{kN}-\mathrm{m}$ was achieved at $t=0.152 \mathrm{sec}$. In addition, $M_{0, \max }$ was only $13 \%$ higher than the steady-state restraining moment $(99.8 \mathrm{kN}-\mathrm{m})$. In addition, the restraining moment corresponding to beam static loading capacity must be higher than the restraining moment measured at the steady-state. It can therefore be concluded that, as
Table 4 Overall loading capacity of specimens.

\begin{tabular}{c|c|c|c}
\hline Specimen & $P_{y u}(\mathrm{kN})$ & $P_{u, \min }(\mathrm{kN})$ & $P_{u, \min } / P_{y u}$ \\
\hline \hline $\mathrm{D} 1$ & 25.1 & 23.9 & 0.95 \\
\hline $\mathrm{D} 2$ & 25.0 & 44.0 & 1.76 \\
\hline $\mathrm{D} 3$ & 33.8 & 54.6 & 1.62 \\
\hline $\mathrm{D} 4$ & 43.0 & 44.0 & 1.02 \\
\hline
\end{tabular}

compared with the compressive arch action, loading rate may have insignificant effects on the beam flexural strength of Specimen D2.

The enhanced beam flexural strength improved the overall load capacity of the specimens. $P_{u \text {,min }}$, the minimum load capacity, for the three longitudinally restrained specimens is given in Table 4 and compared with $P_{y u}$, the load capacity without considering the longitudinal restraining effects. It is seen that from this table that the compressive arch action enhanced the load-carrying capacity by at least $76 \%$ for Specimen D2 and $62 \%$ for Specimen D3.

The extra strength provided by compressive arch action indicates that the frame beams of some existing structures, especially those designed for seismic loading, may possess much higher progressive collapse resistance than typically assumed. On the other hand, as discussed earlier for the nonlinear SDOF system, if the enhanced flexural capacity is neglected, the dynamic deformation demand on a beam could be significantly overestimated.

\subsection{Dynamic amplification effects for forces}

Similar to seismic design provisions, DOD $^{2}$ classified two types of actions that must be considered in the design and evaluation of building progressive collapse. They are the deformation-controlled actions such as flexure, and the force-controlled actions such as shear for reinforced concrete members. The underlying philosophy is that, under any circumstance, a structural member shall not fail in a brittle mode due to forced controlled actions. In the seismic design of reinforced concrete beams and columns, the shear demand is estimated based on equilibrium requirement and the maximum probable moment acting on each end of the member. However, the DOD progressive collapse guideline ${ }^{2}$ does not adopt this approach for the design of force-controlled actions. Instead, a dynamic impact factor of 2 without considering damping property is used to estimate the dynamic loading effects on the demand of force-controlled actions.

The actual dynamic impact factor is examined in this study using test data. Because the shear force in a beam could not be directly measured in this study, the restraining moment at the supports under lower levels of load that did not cause flexural yielding is used for this purpose. A dynamic impact factor, defined herein as the ratio of peak restraining moment to restraining moment under static loading (determined from steady-state measurement), was calculated for the three longitudinally restrained specimens. The so calculated dynamic impact factors are plotted in Fig. 11 against load $P$. Fig. 11 indicates that the value of dynamic impact factor can be greatly reduced as the gravity load $P$ increases. For instance, the dynamic impact factor is equal to 1.70 for Specimen D4 under the load of $P=8.7 \mathrm{kN}$, and reduced to 1.36 when the load of $P=28.9 \mathrm{kN}$ was applied on this specimen. The much lower dynamic impact on forces than assumed in $\mathrm{DOD}^{2}$ may be explained by the nonlinear stiffness characteristics of a beam 


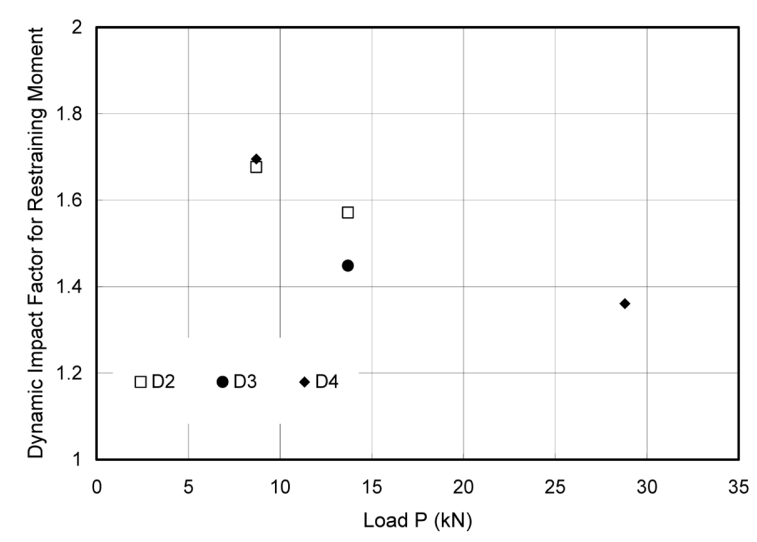

Fig. 11 Dynamic impact factor for restraining moment.

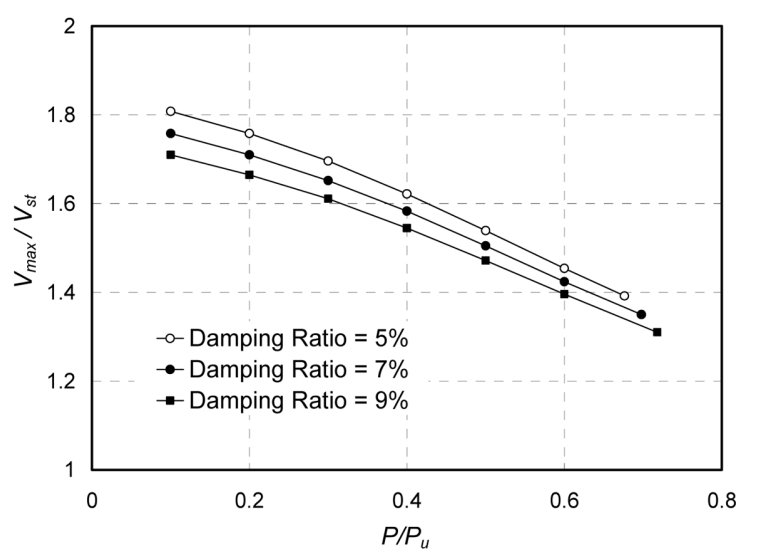

Fig. 12 Effect of nonlinear elasticity on dynamic demand.

demonstrated even prior to its flexural yielding. A specimen experienced the largest deformation during the first cycle of vibration when most concrete cracking occurred. Therefore, the stiffness at the steady-state response can be used to approximate the stiffness of a specimen at its peak deformation. Secant stiffness, defined as the ratio of load $P$ to the steady-state center deflection, was calculated for Specimen D4 at two load levels prior to yielding. It was found that, at $P=8.7 \mathrm{kN}$, the specimen has a secant stiffness of $1.96 \mathrm{kN} / \mathrm{mm}$, but at $P=28.8 \mathrm{kN}$, the secant stiffness dropped dramatically to $1.09 \mathrm{kN} / \mathrm{mm}$.

To illustrate the effects of nonlinear stiffness property on dynamic impact, the response of a SDOF system was studied. The SDOF system is identical to that shown in Fig. 1, except that a third-order polynomial as shown in Eq. (9) was assumed to define a nonlinear elastic relationship between force $P$ and deformation $u$ prior to yielding. $k_{0}$ is the initial tangent stiffness in this equation. This constitutive relationship defines a 50\% secant stiffness reduction (compared with the initial stiffness) and a 75\% tangential stiffness reduction at yielding. Such gradual stiffness degradation has been observed in the static loading tests ${ }^{12}$. Different levels of step force were applied and the dynamic responses were numerically evaluated. Fig. 12 shows the dynamic impact factor, calculated as the ratio of the maximum dynamic shear force $V_{\max }$ to the static shear force $V_{s t}$, as a function of load level expressed as the $P / P_{u}$ ratio for the SDOF system using three different damping ratios. The data points with the largest value of $P / P_{u}$ in Fig. 12 are associ- ated with the loads that result in the reach of $P_{u}$. Fig. 12 indicates that, with the assumed nonlinear elastic property, dynamic impact on forces reduces as the load level increases. At the highest load levels (leading to the reach of $P_{u}$ ), the dynamic response factors are less than 1.5 for all damping cases. Thus, according to the test data and the aforementioned SDOF system analogy, the stiffness properties of a beam resisting progressive collapse should be defined with special care in a dynamic analysis to obtain a realistic estimation of the dynamic demands for the force-controlled actions such as shear.

$$
P=\frac{k_{0}^{3}}{16 P_{u}^{2}} u^{3}-\frac{3 k_{0}^{2}}{8 P_{u}}+k_{0} u
$$

\section{Summary and conclusions}

The study presented in this paper experimentally investigated the dynamic response of reinforced concrete beams subjected to the instantaneous removal of a supporting column. The load-carrying capacity and dynamic impact on forces were examined. Based on the test results, the following major conclusions can be reached:

1) Under the dynamic loading conditions considered in this study, compressive arch action could still be developed in the longitudinally restrained two-span beams. For the specimens with moderate reinforcement ratios, compressive arch action increased the load-carrying capacity by as much as $60 \%$. Compressive arch action can be considered for the beams resisting progressive collapse to achieve an economical solution.

2) The dynamic impact in terms of forces decreased with the increased load levels. The dynamic impact factor was less than 1.4 under the highest level of loads that did not cause flexural yielding. The traditional use of constant stiffness to define the elastic property of a beam bridging over the lost column in a dynamic analysis may significantly overestimate the dynamic force demand.

\section{Acknowledgements}

The authors gratefully acknowledge the financial support provided by the National Natural Science Foundation of China (No. 50478114) for the work presented in this paper.

\section{References}

1. American Society of Civil Engineers (ASCE), Minimum Design Loads for Buildings and Other Structures (ASCE 7-10), American Society of Civil Engineers, Reston, VA., USA, 2010.

2. Department of Defense (DOD), "Design of Building to Resist Progressive Collapse," Unified Facility Criteria (UFC 4023-03), 2009, Washington, DC., USA.

3. American Concrete Institute, Building Code Requirements for Structural Concrete (ACI 318-08) and Commentary (318R08), ACI Committee 318, 2008, Farmington Hills, Mich., USA.

4. Hayes, J. R. Jr., Woodson, S. C., Pekelnicky, R. G, Poland, C. D., Corley, W. G., and Sozen, M., "Can Strengthening for Earthquake Improve Blast and Progressive Collapse Resistance?" 
Journal of Structural Engineering, Vol. 131, No. 8, 2005, pp. $1157 \sim 1177$.

5. Sasani, M. and Kropelnicki, J., "Progressive Collapse Analysis of an RC Structure," The Structural Design of Tall and Special Buildings, Vol. 17, No. 4, 2008, pp. 757 771.

6. Sasani, M. and Sagiroglu, S., "Progressive Collapse of Reinforced Concrete Structures: a Multihazard Perspective," ACI Strucural Journal, Vol. 105, No. 1, 2008, pp. 96 103.

7. Bao, Y., Kunnath, S. K., El-Tawil, S., and Lew, H. S., "Macromodel-Based Simulation of Progressive Collapse: RC Frame Structures," Journal of Structural Engineering, Vol. 134, No. 7, 2008, pp. 1079 1091.

8. Marchand, K., McKay, A., and Stevens, D., "Development and Application of Linear and Non-Linear Static Approaches in UFC 4-023-03," Proceedings of 2009 Structures Congress, ASCE, Austin, TX, USA, 2009, pp. 1729 1738.

9. Ellingwood, B., Marjanishvili, S., Mlakar, P., Sasani, M., and Williamson, E., "Disproportionate Collapse Research Needs," Proceedings of 2009 Structures Congress, ASCE, Austin, TX, USA, 2009, pp. 1896 1907.

10. Sasani, M., Bazan, M., and Sagiroglu, S., "Experimental and Analytical Progressive Collapse Evaluation of an Actual Reinforced Concrete Structure," ACI Structural Journal, Vol. 104, No. 6, 2007, pp. 731 739.

11. Sasani, M. and Sagiroglu, S., "Progressive Collapse Resistance of Hotel San Diego," Journal of Structural Engineering, Vol. 134, No. 3, 2008, pp. 478 488.

12. Su, Y., Tian, Y., and Song, X., "Progressive Collapse Resistance of Axially-Restrained Frame Beams," ACI Structural Journal, Vol. 106, No. 5, 2009, pp. 600 607.

13. Wei, W., Quintero, R., Galati, N., and Nanni, A., "Failure Modeling of Bridge Components Subjected to Blast Loading, Part I: Strain Rate-Dependent Damage Model for Concrete," International Journal of Concrete Structures and Materials, Vol. 1, No. 1, 2007, pp. 19 28.

14. Quintero, R., Wei, J., Galati, N., and Nanni, A., "Failure Modeling of Bridge Components Subjected to Blast Loading, Part II: Estimation of the Capacity and Critical Charge," International Journal of Concrete Structures and Materials, Vol. 1, No. 1, 2007, pp. 29 36.

15. Chopra, A. K., Dynamics of Structures, Third Edition, Pearson Prentice Hall, 2007, 876 pp. 